\title{
THE TRANSLATION OF TV COMMERCIALS. DEGREES OF LOCALISATION
}

\author{
Diana OŢĂT* \\ University of Craiova, Romania
}

\begin{abstract}
The paper aims at featuring some current advertising trends and their effect upon the remapping of translation strategies. Addressing the field of advertising from a translationoriented perspective, we seek to look into how TV commercials' relocation is tackled in view of the unity in diversity socio-cultural context and to investigate the cultural intake. Hence, we set out to establish to what extent broadcasted stereotypes are disseminated via translation. Special attention is paid to the role of the cultural variable and the translation of culture-specific elements in terms of localisation and glocalisation. To shed some light on the issue of stereotyped interfaces and the overcoming of crosscultural barriers in the translation of TV commercials, we embark upon a specialised corpus-based analysis of a set of "globalised" commercials by means of dedicated software.
\end{abstract}

Keywords: CAT tools, cultural variable, glocalisation, localisation, translation strategies

\section{INTRODUCTION}

As outcome of a collective process of interdependency among contemporary societies, advertising plugs modern consumers into the globalised market, hence two main polarizing approaches seem to overlap: uniformity and multiformity. On the one hand, researchers within various contemporary occupational sectors pinpoint a constant tendency towards homogenization as a panoptic strategy that applies to almost all current activities. Translated as standardisation, uniformity has been adopted to the fields of marketing and advertising, driven by an everincreasing need to cover vast advertising activities across different international markets. Assisted by technology transfer and communication, standardisation strategies aim at boosting incomes, while securing globalised market-control and

*otatdiana@gmail.com 
monitoring, despite the distinctive characteristics that feature each and every socio-cultural setting. However, recent approaches to advertising warn against an inconsistency-based phenomenon, due to cultural variations among consumers, which may obstruct effective marketing developments, diminishing creative spirits and returns.

Under the circumstances, a steady tendency has been recorded with regard to the strategy of localisation since the early 2000s, first with the issuance of the Translation Memory eXchange (TMX) standard by LISA (Localization Standards Industry Association), and further developed by GALA (Globalization \& Localization Association). According to this standard, localisation is "the alteration of any aspect of a product or service that is needed for a product to be sold or used in another market.” Hence, LISA's definition of localization states that it "involves taking a product and making it linguistically and culturally appropriate to the target locale (country/region and language) where it will be used and sold" (LISA 1998: 3).

Featured by Pym as "the showcase market strategy of international capitalism" (6), localisation is described by Dunne as a "process by which digital content and products developed in one locale (defined in terms of geographical area, language and culture) are adapted for sale and use in another locale.” (4)

All the same, localisation means both uniformity and multiformity, for it is not until a product becomes internationalised (neutralised) that localisation strategies need to be applied (customised). In other words, the product and the accompanying advertisement undergo an almost similar process as the process of translation, since we need to decode (neutralise) and encode (adapt) the advertising message in the target language and culture to further make it available for all individuals that belong to a certain language community, i.e. to globalise it.

Within this context, various scholars advocate that localisation encompasses two key constituents: adaptation and custom-tailoring, applied to secure the release of a product in compliance with target market characteristics, since "If I'm selling to you, I speak your language," but "If I'm buying, then you must speak German!” (Willy Brandt)

\section{LOCALISATION IN ADVERTISING: A TRANSLATION-ORIENTED PERSPECTIVE}

Having set language and culture as main variables to fulfil customers' needs, scholars have grown aware of various particularities that feature each target market. From climate conditions to different educational institutions, legal systems, religious constraints and social standards, an exhaustive inventory of variations shall reflect consumers' heterogeneous profile, calling upon the 
setting of a "cultural filter", because of "the uniqueness of the cultural-historical context" (House 196) and the non-transferable idiosyncrasy from the source culture to the target culture.

It is the presence of this "inborn" physiognomy that makes both advertisers and translators resort to adaptation and custom-tailoring methods to meet specific socio-cultural habits, preferences, rules and regulations. Hence, we come to understand localisation as a different-degree form of alteration.

On the subject of translation, researchers within the field of advertising and translation recommend adaptation as an implementing measure to secure localisation. Accordingly, the linguistic content is adapted to the cultural background, which grants even for the altering of original fonts, size of the text, and colours. An example as banal as it is successful remains Coca-Cola, a brand that carries over the values and the symbols of the American Dream, available in almost every country, yet acclimatised differently. The localisation strategy applied by Coca-Cola targeted not only customisation in terms of logo fonts, size and colour, but also adaptation, i.e. the translation of the product name in different languages, in compliance with specific linguistic and cultural requirements. Thus, for the Chinese, Coca Cola means "delicious happiness," literally inscribed with the well-known white letters on a red background as kekouke le, whereas in Hindi, Coca Cola is written as $\square \square \square \square \square \square \square \square$. But Coca Cola does not limit to linguistic adaptation, for in the last two decades, promoters launched different colour-based campaigns to resonate with different cultural habits and symbols. Therefore, the American silver-background Diet Coke crossed the Atlantic into the black-background Coca Cola Zero.

Obviously, each advertising project that implies localisation requires distinctive implementation methods. Both advertisers and translators would observe a multi-faceted strategy related not only to the type of product and its accessibility, but also to the target audience access to media channels.

Before embarking upon an advertising campaign and its release on a certain target market, it is almost mandatory that the cultural background be analysed and comprehended. The strategy of localisation would then imply not only the plain translation of a message from the source language into the target language, but also, an in-depth investigation of cultural particularities, an "intercultural activity" rather than "an interlinguistic process", as recommended by Gentzler (186), where the cultural setting becomes the "translation unit" instead of text, as endorsed by Snell-Hornby (40).

Paradoxically, when advertising a product overseas, the core rules do not necessarily demand a thorough investigation of cultural particularities, but rather a close analysis of target culture restrains, from political and religion-based constraints to education, customs and even coloristic-based restrictions, to become familiar with foreign inherited traditions via "domestication" as advocated by Lefevere (76). Thus, sometimes it may even happen that due to 
considerable cultural differences between the source and the target cultures, whole advertising campaigns need customisation or even redesign to better blitz the target culture market. Parallel to cultural insights within the target market, special attention needs to be paid to the translation of the source message into the target culture as well - a multistage process, judiciously set up before carrying out any task of translation.

Strategically, it is first to be established whether the advertised product and message can be localised, or the entire campaign needs to be remapped. Also, the degree of alteration is to be decided, i.e. to what extent the source culture message may undergo particular deviations in compliance with specific features of the target language to secure effective assimilation into the native culture. Just as important is the selection of suitable dedicated tools and technologies that assist translators to input, process and deliver a multilingual outcome, further released "in global media networks and the audio-visual marketplace" (Baker 1).

The mapping of the strategic framework is followed by a prospective analysis, carried out in terms of effectiveness and impact. Translators shall test whether cultural or functional equivalence would need to be applied, hence securing an impact at least as forceful as in the source-market. Based on the outcome of the analysis stage, translators step forward to design comprehensive checklists, meant to assist them develop a localisation kit that implies:

- the design and development of thematic maps;

- analysis and pre-translation of texts via CAT tools and dedicated software;

- technological skills development with regard to machine translation applications and resources;

- translation memory management;

- design and development of digital corpora encompassing source and target files;

- continuous updating of previous translations;

- checking the consistency and the impact of translations;

- linguistic quality assurance;

- layout and linguistic problems that need to be identified and fixed before a product release.

Further analysis subsequent to the translation stage is aimed at tracking both clients' and customers' feedback, since the quality of the localised product requires compliance with the quality assurance norms in force. Such contemporary marketing strategies, based on localisation-oriented approaches, are meant to increase incomes and intensify sales.

Just like Coca Cola, MacDonald's adopted the strategy of advertising relocation in view of the unity in diversity socio-cultural context.Though 
manifested at different levels, the most visible shift towards localisation is the very translation of the long-lasting global slogan I'm loving it, played nowadays in other languages as well, i.e. Me encanta in Spain, or Ich liebe es in Germany. Such examples reinforce the importance of both cultural and linguistic variables that need to be observed when localisation is applied.

Resultantly, localisation as applied both to marketing and translation is resourcefully focusing on customers' linguistic and socio-cultural particularities. We come to understand that these two core elements, language and culture, need to be observed, tailor-made and accommodated in order to be further used as a driving force that enhances responsiveness and boosts incomes and share markets.

\section{THE ISSUE OF STEREOTYPED INTERFACES AND THE OVERCOMING OF CROSS-CULTURAL BARRIERS IN THE TRANSLATION OF TV COMMERCIALS}

Coined from the heart of societies' cultural uniqueness, the phenomenon of stereotyping developed as a category yardstick to tag individuals within a certain group or community, based on origin, language, appearance, etc. Although perhaps as old as the collapse of the Tower of Babel, this practice still functions and is applied to modern individuals, highly affecting personal and professional development, hence diminishing productivity and profit.

\subsection{THE CONCEPTUAL FRAMEWORK OF CULTURAL DIMENSIONS}

Featuring culture as the key element that brings together and separates at the same time smaller or larger human communities via similar or highly distinguished features, Hofstede (6-7) defines this concept as "the collective programming of the human mind that distinguishes one group or category of people from another," since culture as a collective phenomenon, it is "at least partly shared with people who live or lived within the same social environment." According to the Dutch social psychologist, culture manifests differently, at "different levels of depth," though unfolding the same "skins" (Hofstede 8). The Onion Diagram, as put forward by the author, illustrates that each socio-cultural setting is characterised by the same number of cultural dimensions. Yet, the content of each layer is different from one society to another. Adopting a bottom-up-approach to culture, the author places at the core of the onion specific values of each community, i.e. the deepest most opaque manifestations of culture, then, in turn, just like onion-layers, all the other strata reveal a particular cultural landscape, with heroes and rituals in between, followed by national symbols, the most superficial (transparent) layer. Then, these specific values, 
rituals, symbols and even artefacts of a society are transferred from generation to generation, shaping particular collective features each community exhibits. Consequently, societies can be described within their own cultural framework, enabling us to understand what reactions are likely and understandable, given one's past. However, this outline of cultural dimensions does not manifest in isolation. Contemporary cultural programming is constantly updated via interdependent affairs among the states of the world, while the ever-increasing globalised market brings individuals of most remote communities together. Under the circumstances, stereotyping seems to be inevitable. Modern anthropologists, sociologists, socio-linguists and translators have sought to identify and investigate behavioural and social particularities that differentiate individuals belonging to different cultural backgrounds, hence profiling different socio-cultural dimensions.

Hofstede (92-102) distinguishes between five different cultural dimensions:

- Power distance index (superior/subordinate relations)

- Individualism versus Collectivism

- Masculinity versus Femininity

- Uncertainty avoidance index

- Long term orientation versus short term orientation in life

Trompenaars and Hampden-Turner developed the model put forward by Hofstede and established seven cultural dimensions to feature human communities:

- Universalism versus Particularism

- Individualism versus Communitarianism

- Specific versus Diffuse

- Neutral versus Emotional

- Achievement versus Ascription

- Sequential time versus Synchronous time

- Internal direction versus Outer direction

Despite globalisation tendencies, and despite borders' fall and the European citizenship status, socio-cultural particularities and stereotyping remain a contemporary reality. We still come across stereotyping in various fields of activity, and advertising, as a modern form of communication, is no exception.

The question that is to be raised is how and why the dissemination of stereotypes via advertising, including commercials, highly impacts upon members of different communities, given their different cultural setup. A twofold approach seems to have been applied to commercials' broadcasting and their translation.

From a standardised perspective, we would regard stereotypes' dissemination as a consequence of globalisation, a tendency towards uniform and homogenous approaches to daily contemporary routines. Implicitly, the 
translation of such messages is merely reduced to the transfer of a certain stereotype in the target language. Of course, stereotypes' dissemination would only be possible if related to the most transparent layers of a culture, i.e. national and/or socio-cultural symbols, the easiest to identify and assign. Or, they can be the product of a contemporary globalised (standardised) collective programming.

We consider that this is, for example, the case of the Walk-In Fridge Heineken commercial. Launched in 2009, initially in the Netherlands, the commercial makes allusion to a long-lasing gender stereotype, the different affinities of men versus women, especially concerning beer, still perceived as a man's drink. The same commercial was broadcasted and translated into different languages, including English and Romanian. Preserving the same scenario and cast, and, keeping faithful to the original message, the Romanian version of the commercial pictures a young couple making the tour of their new apartment to friends. While the female friends burst into cries of delight when walking in a huge dressing room, their male partners manifest the same reaction when walking in a huge fridge filled with bottles of Heineken. Closely related to the masculinity versus femininity cultural dimension, the commercial and the enclosed stereotype had a similar surprising impact in highly feminine societies, such as the Netherlands, as well as in other, rather masculine ones, such as Romania.

Another example in this respect is the 2018 Star and Laurel MercedesBenz S-Class Commercial. Although in western cultures, the Germans and the English are featured as long-term oriented and achievement-based individuals, in comparison to south-eastern societies, which manifest a short-term orientation in life, mainly based on ascription, this commercial, and implicitly the stereotype carried over, have an almost similar impact among differently programmed mind-sets. Introduced to a continually innovative engineering environment, the target audience is motivated to follow Mercedes-Benz good practices model, to push technological development further, in what could be regarded as a constant call for best achievements.

It is still debatable if stereotyping, whether intentional or not, could have been avoided via translation, without diminishing the impact upon the target audience, whether it is intentional or not.

By approaching stereotype dissemination in terms of localisation, both advertising and translation would no longer imply unintentionality, since, via localisation, the message would be translated, tailor-cut and accommodated to the target customers. For example, the Sheer Volume Pantene Pro V commercial, has been localised, i.e. adapted for the Romanian market. Based on the same scenario, both content and message have been customised to meet Romanian women's expectations. A local female model replaced the protagonist of the original spot as a domestic embodiment of beauty and strength. A vocative text, the translated slogan was adapted so as to secure a high impact upon the target 
audience: Go up a hair size! - Dă volumul la maxim! Though subject to the process of localisation, the stereotype advertised by this commercial is not only carried over, but also tailor-made and adapted in compliance with Romanian female beauty prototype.

We find the same strategy in the 2017 Nestlé Cereals UK TV Commercial and its Romanian counterpart. Both commercials are based on the still in vogue stereotype of healthy bio nutrition, sharing the same background and the same feminine voice that encourages consumers to choose the "whole grain no. 1 ingredient" ("cerealele integrale nr.1") and to "look for the green banner Nestlé" ("caută simbolul verde Nestlé"). In this case, however, localisation has been applied both in terms of message and product. If the keyterms of the British commercial highlight the benefits of the products to be "high in fibre" and have "no artificial colours or flavours", the message transferred into Romanian focuses on vitamins and minerals ("vitamine și minerale") for a balanced diet ("pentru o alimentaţie echilibrată"). Moreover, the products advertised are not identical, either the names, or the ingredients. Hence, localisation has been applied based on the nutrition and culinary education of the two cultural settings of a healthy life stereotyped concept, differently perceived within different communities.

\subsection{THE CULTURAL VARIABLE TRANSFER THROUGH LOCALISATION AND GLOCALISATION}

As actors on today's world stage, driven by collaborative initiatives, from economic and trade affairs to social, cultural and political activities, all of them facilitated via translation, we grow aware that the field of Translation Studies intensified, while developing highly specialised ramifications, triggered by the wide variety of modern activities. The paradigm shift of the new millennium reshaped the field of translation due to "various forms of linguistic and cultural mediation" (Baker 19). We could thus outline the configuration of a composite assembly, approached from different multi-, inter- and transdisciplinary perspectives, both as process and product.

The modern world translation practice had to face an ever-increasing global publishing industry, novel practices carried out by multinational companies, as well as the development of two modern industries, advertising and film production. Also, the processing and the delivery of translated materials (form, shape and communication channels) has undergone considerable change with regard to translation deliverables. Thus, not only was the output of translation reshaped so as to meet contemporary market demands, but so did translation strategies and tools. Nowadays we talk about localisation and glocalisation as highly circulating translation strategies. 
A brief outline of the mainstream literature would lead us towards a twodimensional perspective of the contemporary translation landscape, a confluence of two polarised trends that feature the contemporary status of translation. Reviewing the previous sections in a few words, we reinforce the productive role and the function of localisation, as a strategy of alteration, customization and adaptation, as opposed to what Beck (qtd. in Sarcevic 111) described as "an allencompassing cultural and social phenomenon which undermines traditional cultures and societies in their struggle for power and identity”. Localisation is then the alteration of the already implemented source output to meet the requirements of the target culture and language. Via localisation, the already exploited source end-product (goods or messages) is expressly adjusted to suit another language and culture. Translation secures accommodation, while adapting the source product to the target language, its cultural, political and legal dimensions.

In terms of translation, the strategy of localisation is applied both at a cultural and linguistic level, and translators would need to compile an adapted message in order to overcome linguistic barriers, giving life to a product that crosses borders. At the linguistic level, an echoing target message should observe alteration in terms of:

- Typographical or logographic changes, the use of abbreviations and acronyms as in:

o Diet Coke (USA) - Coca-Cola Light (EU);

o Dr.Oetker(EU) - Cameo (IT) - though the brand name Dr. Oetker is standardised almost over the world, in Italy, it was localised as Cameo, preserving though the same logo;

o Vauxhall (GB) -Opel (EU) - apparently two different vehicle models, Vauxhall and Opel, are one and the same car, the first localised in Great Britain, while on the Continent it is sold as Opel. In this case, not only the name, but also the logo was changed.

- Abbreviation and acronym localisation is also frequently applied, for example:

o USA (En.) - SUA (Ro.);

o ZIP (En.) - CP (Ro.);

o VAT(En.) - TVA (Ro.).

- Punctuation marks can be changed via translation in order to preserve the original message:

o (Ro.) 25.000 Euro -(En.) 25,000 Euro.

- Diacritics may also cause problems, especially in product advertising:

o Müller (Germ.), Gösser (Germ.) BRD GroupeSociétéGénérale (Fr.) 
- Adaptation is also required to transfer different units of measure into the metric system successfully, like:

o 1 foot (ft) $=12$ inches (in), 1 Pound $=0$, 45 Kilogram, 0 deg

Celsius $=32$ deg Fahrenheit

- Address formats also vary:

\begin{tabular}{|l|l|}
\hline EN & RO \\
\hline Ms Jane Dune & Dna Ionescu Dana \\
12 Westgate & Str. Unirii, nr.3, 20456 \\
Basildon, Essex & CRAIOVA, \\
ENGLAND SS14 1WP & DOLJ, ROMANIA \\
\hline
\end{tabular}

- Time and date formats: a variety of conventions and formats for time and date have been used or adopted by the same language and different languages. In other words, the elements of time and dates have been put in different orders in different languages.

o 07-15-2017 (American English), 15-07-2017 (French and German).

Based on the key concepts in localization, recent developments branched off to the translation of local realities into a global language, hence the concept of glocalisation, a synthetic paradox that brings together the trend of globalisation, i.e. the proliferation of networking and interdependence, and, the strategy of localisation under the shape of customisation and distinctiveness. Glocalisation is a completely different concept from globalisation. A relatively new term that emerged in the 1990s, and closely related to the Global Change Exhibition in the German Chancellery in Bonn, glocalisation seems to be rooted in the Japanese expression of dochakuka, which, according to Oxford Dictionary of New Worlds (Tulloch 134), emerged as an agricultural practice of accommodating farming techniques to local circumstances, i.e. global localisation. A reversed perspective of localisation, the strategy of glocalisation aims primarily at matching the source output the foreign market. The source product is no longer customised or adapted to meet targeted markets requirements after homeland testing, but is designed and developed so as to directly fit target markets. We no longer deal with "copies" of the "original”, as highlighted by Bassentt and Trivedi (132), to colonise the dominant-culture influence in minority-status target culture, but with a communicative translation to convey the most precise contextual meaning, a "transcultural" action as labelled by Nord to "conform as far as possible to the situational conditions of the addresses” (46). Admittedly, such glocalised products would automatically 
appeal much more to the ultimate user, as their original concept was primarily intended for the global market, and then customised to suit a target culture.

Among multinational companies to have adhered to the current glocalisation landscape is MacDonald's. New TV commercials broadcast more and more glocalised products under the much-publicised umbrella brand. A typical example for the Romanian market is the 2013 MacDonald's commercial for McMici. Re-interpreting specific cultural artefacts, MacDonald's glocalises the traditional Romanian grilled minced meat rolls (cultural equivalent of the Balkan ćevapčići dish) and customises the product as a grilled minced meat burger, i.e. the McMici - introduced by a re-make of MacDonald's famous jingle tuned to a Romanian folk melody. Of course, Romania is not the only market that advertises MacDonald's glocalised products, similar examples are the Mexican Mac Patatas, the Spanish Coulant Nocilla, the Japanese McTeriyaki, or the Indian Chicken Maharaja-Mac.

Another example of glocalisation, though at a smaller scale, is the commercial of a Romanian automotive manufacturer and its specially designed model for the global market. The 2017 Dacia Duster TV commercial Another one drives a Duster accommodates the Romanian vehicle Dacia Duster to some British-specific settings of fine tailors, birdwatchers and Scottish shepherds. The message is delivered entirely in English, and, as eccentric as it may seem, it bears Romanian subtitling when broadcasted in homeland.

A first conclusion with regard to the current development of the translational landscape within the modern world would highlight a mirror-image approach, where two antipodal perspectives, play their role in bridging cultures and facilitating people to better communicate among each other.

To put it in a nutshell, glocalisation applied to advertising translation could be regarded as an upgraded version of "instrumental translation" - the production of an "object text in its own right, directed at a target-culture" (Nord 49) to fulfil culture-specific norms, traditions and preferences. Conversely, localisation has become the inverted strategy for "globalizers such as CNN, Newsweek, and Cosmopolitan" who, in their attempt to open up new markets, "have to adapt the content to local requirements and sensitivities" Baker (20).

\section{DEGREES OF LOCALISATION IN TV COMMERCIALS: COMPUTER-ASSISTED CORPUS DESIGN AND ANALYSIS}

We agree to the perspective put forward by Baker that cutting-edge technology and especially computer-assisted tools are of paramount importance in the contemporary job of a translator, acting as "participatory culture that makes many of the challenges posed through translation and interpreting possible" (23). 
To keep up with the almost instant changes of nowadays' local and global markets, translators need to map out new strategies. Computer-assisted localisation is aimed at fastening the process of translation, securing, on the one hand, time-effective outcomes and, on the other hand, the development of thematic maps and word banks to be constantly updated and re-used for further translation projects.

A relatively new computer-assisted tool that translators can resort to for various tasks is MAXQDA, data-analysis software, used especially for the design of thematic maps and specialised word banks. A novelty in the use of CAT tools brought on the market by MAXQDA developers is the Max-Dictio module. The tools provided by this module enable users to carry out effective quantitative analyses applied to visual text exploration, content analysis, vocabulary analysis, and dictionary-based analysis. From single words to entire word combinations, these tools can display all word locations and their context in table formats, or, they can record and illustrate frequencies, ranks and distribution of word combinations and even filter them according to users' particular interests. A dictionary-based analysis may assist users to define categories of search terms, the occurrence of which one can then measure and compare. Also, it is worth mentioning the networking option provided by the software. It enables users from all over the world to connect and work together within the same virtual environment for simultaneous projects.

Joining a translation project, as part of an international team, or submitting some local translation quotation, translators may use MAXQDA to:

- design, develop, store and share term databases;

- design and share term lists to preserve consistency when applied to particular fields of specialisation;

- develop technological and networking competences to boost translation expertise;

- guarantee effectiveness and reliability within regional or international translation projects;

- communicate in real-time with project members in terms of revision and proofreading of the same files.

To analyse the degree of localisation in some of the previously exemplified TV commercials, we embarked upon a computer-assisted analysis via MAXQDA.

First we designed a parallel corpus of 3 commercials, considered to have undergone adaptation when translated into Romanian. It is worth mentioning that the commercials were downloaded from the YouTube Official Channels of the brands analysed, i.e.MacDonald's - Grand Big Mac (Ro./ En.), Nestlé Nestlé Cereals (En.) Cerealele Nestlé (Ro.), Dr Oetker - Pizza Ristorante (Ro./En.).

As we were mainly concerned with the linguistic dimension of the Romanian texts, we sought to investigate to what degree key structures, central 
to the topic of the commercials, are localised via translation as instances of cultural adaptation or target language accommodation. Consequently, both qualitative and quantitative analysis methods were applied to the corpus.

By carrying out our computer-assisted simulation, we aimed at testing the effectiveness and sustainability of the options provided by the software to feature the TL linguistic output. Our TL audio-medial sub-corpus was then investigated in terms of internal coherence and consistency as compared to the SL sub-corpus. Accordingly, special attention was paid to the frequency rate of globalised (standardised) vs. culture-specific (localised) terms/structures. Based on our computer-assisted frequency-based analysis of standardised vs. localised terms/structures, we simulated the design of a food-related word bank that can be further developed and re-used within the field of food advertising translation.

At a pre-analysis stage, we converted and downloaded the official videos of the 3 pairs (En.-Ro.) of commercials, broadcasted via YouTube. The next step was to import the $4 \mathrm{mv}$. format of the commercials into the software by selecting the option Import Document. The audio-medial corpus was then organised into two parallel sub-corpora: SL COMMERCIALS - EN. and TL COMMERCIALS $-\mathrm{RO}$.

The next stage was to encode certain audio segments of our corpus by selecting the Code option. First, we set out to establish a frequency rate of TL globalised (standardised) vs. customised (localised) terms and structures by comparison to source videos. Our analysis constants were labelled with orange $\rightarrow$ standardised terms and with blue $\rightarrow$ localised terms. Moving a step forward with our analysis, we set up a frequency-based analysis of TL cultural adaptation instances (marked with purple) versus linguistic instances of localisation (marked with green). After encoding the six imported videos, the software enabled us to activate all six samples, and, using the Document Portrait option in the Document Browser window, we obtained a visualisation of the activated samples, illustrated as a picture via the code colours. Hence, within a few seconds, we could establish a frequency rate of the segments encoded, indicating that the longer the coded segment is, the larger the space of a certain colour is displayed in the visualisation. Figures 4.1 and 4.2 below illustrate the encoding stage and the visualisation of the commercials. 


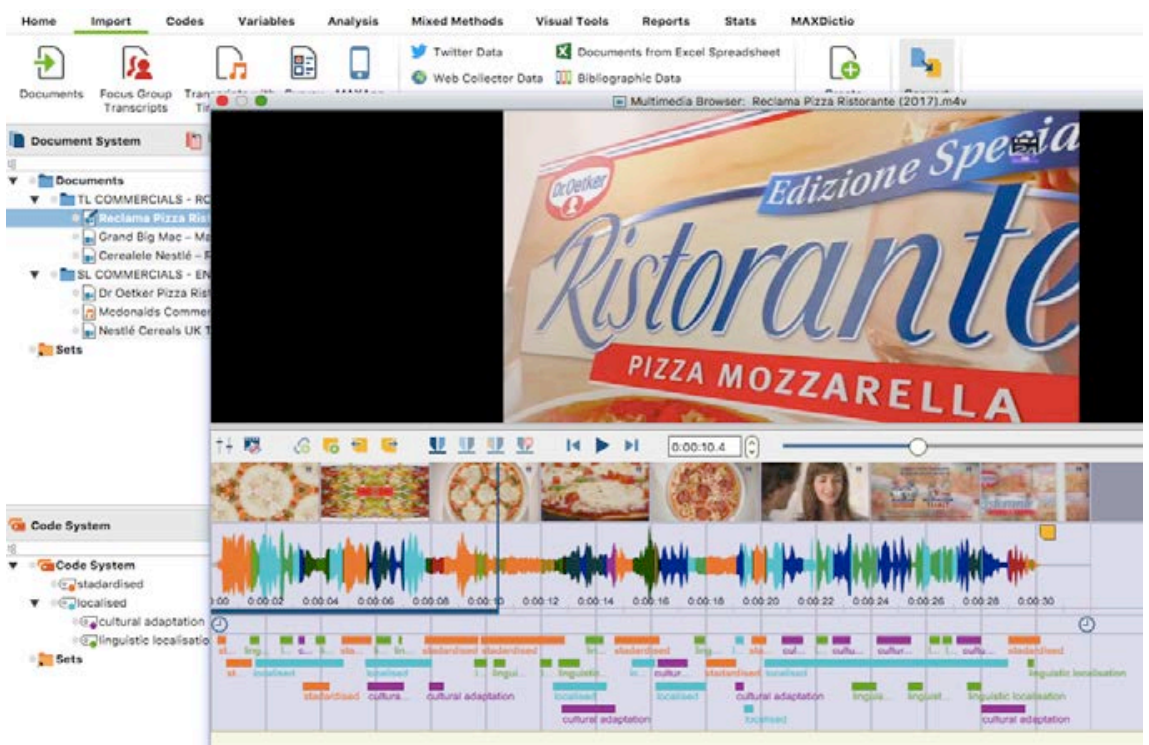

Figure 4.1 Sample encoding

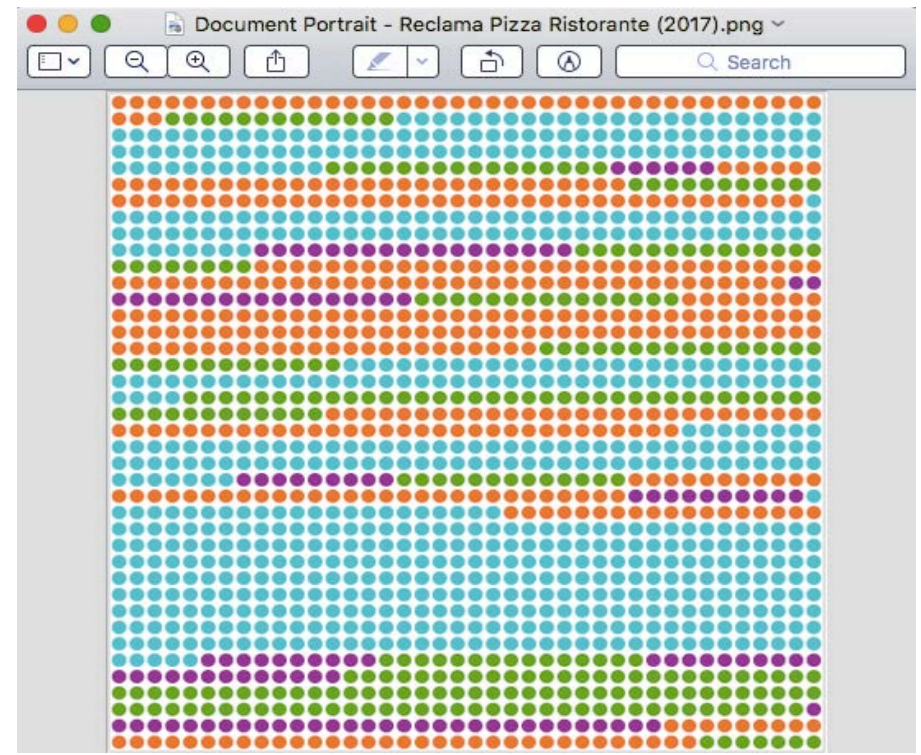

Figure 4.2 Document Portrait: a colour-based frequency rate of the variables set

To interpret the results recorded in the Romanian encoded samples we activated the Code Matrix option, which enabled us to visualise the number of segments coded with each code for each sample. A Code Matrix window opens and we obtain a table-based visualisation of the codes and, at the top of each 
column, the name of the analysed sample. Thus, we can establish the number of encodings for each code in a sample, illustrated as squares. The colour and size of each square indicates the number of the encoded segments. As indicated in Figure 4.3 below, our quantitative survey registered a total of 19 standardised structures/terms in the three investigated samples and 18 localisation instances. Within the 18 localised segments, cultural adaptation was applied 21 times and linguistic localisation 27 times.

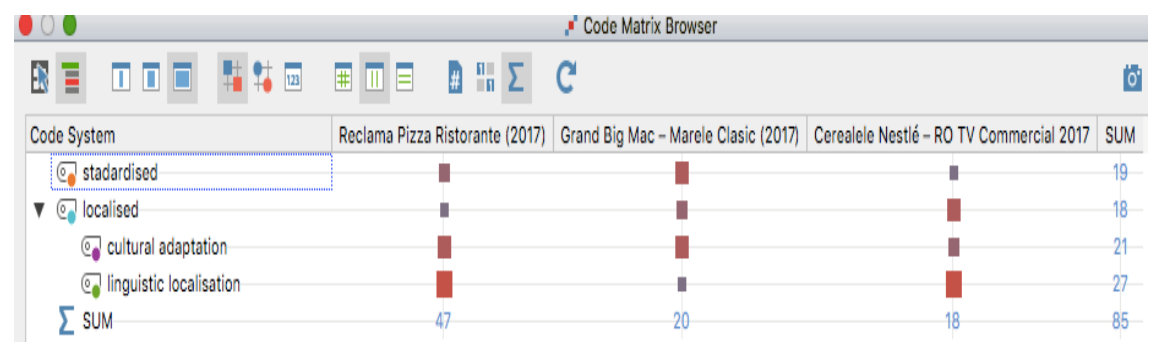

Figure 4.3 Visualisation of results via the Code Matrix option

The encoded segments were then compiled in a word frequency list, a MaxDictio option, that enables us to analyse frequencies, ranks and the distribution of single words, to which we can apply a filter, i.e. a Stop List of negligible words such as prepositions.

A quick visualisation of the word frequency list can be generated as a Word Cloud, where the size of the font is triggered by the number of times a term was found in the 3 samples selected. The software organises the words in alphabetical order, starting in the top left and generates a visualisation of the 50 most frequently-used terms, i.e. the 50 most frequently-used terms of our foodrelated database retrieved form the TL samples.

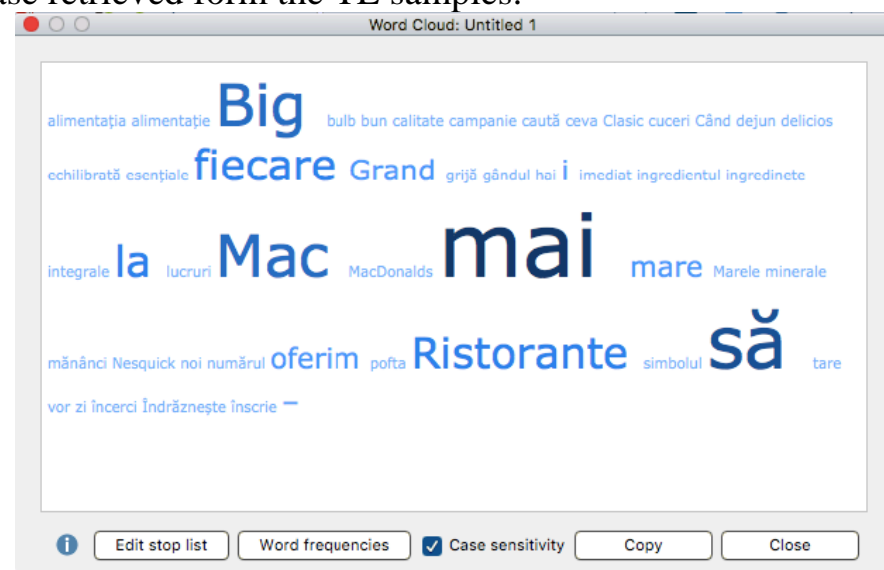

Figure 4.4 Word cloud - degree of localisation 
As the software facilitates users to easily transcribe audio and video files, we could develop a translation-oriented qualitative analysis as well. The Max-Dictio module provides us with user-friendly tools to investigate the content and structure of the samples' wording without new encodings. As illustrated in Figure 4.5 below, the Interactive Word Tree tool helps us to visualise all the combinations that lead to or from any word of our choice, including a detailed display of frequencies. We can thus deepen our investigation of particular structures or terms that can lead to new outlooks, allowing for a comprehensive overview. For example, we could analyse textual and intertextual coherence and consistency - most appropriate translation choices for other field-related transcripts.

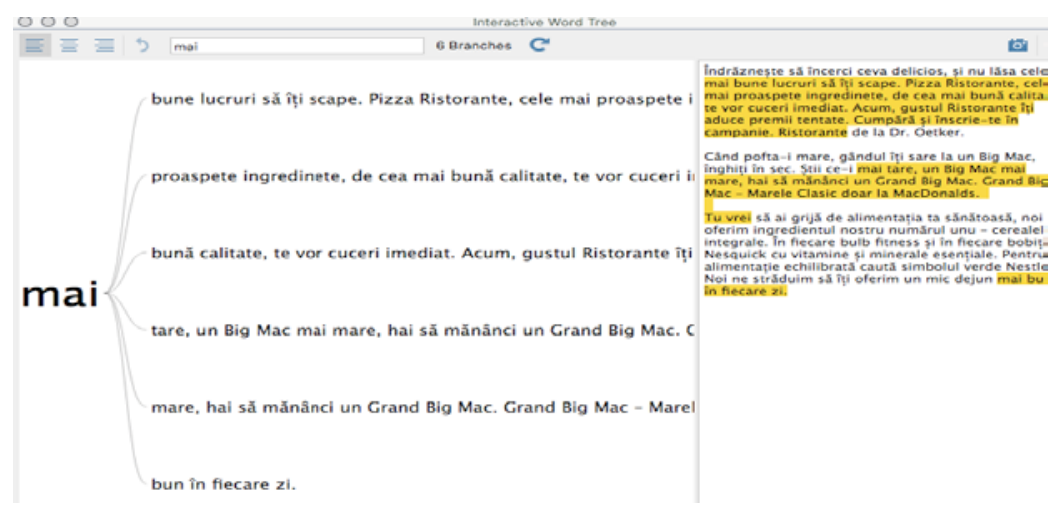

Figure 4.5 Interactive Word Tree to measure coherence and consistency degrees

\section{CONCLUSION}

The emergence of modern channels of communication and the digitalised assisting tools used by contemporary translators have opened novel perspectives on the dynamics of translation strategies.

Dealing with the dissemination of TV commercials in a globalised market biased towards uniformity and standardisation, localisation seems to have saved the day, enhancing responsiveness and boosting incomes. A multifaceted strategy that implies customisation and tailor-cut agenda, localisation is applied in various degrees, at various levels. When it comes to the transfer and adaptation of TV commercials, contemporary strategists apply localisation to translate the textual input into the target language, judicially observing the stylistic conventions of the targeted location. To secure effective assimilation, localisation implies the adaptation of the audio-medial input as well, from religion-based to education, customs, coloristic-based and many other collectiveprogrammed peculiarities that feature a certain cultural dimension. At the same 
time, a mirror extension of localisation, glocalisation disregards the classical dominant-culture influence in the minority-status target culture, focusing to fit the most precise contextual meaning for foreign target markets.

Beyond a shadow of a doubt, globalisation has reshaped the landscape of advertising practices, calling upon integrated translation measures to localise or to glocalise both the product and the message in compliance with the customers' expectations, habits and culture-set attitudes and tastes.

\section{Works Cited}

Baker, Mona. "The Changing Landscape of Translation \& Interpreting Studies". A Companion to Translation Studies, First Edition. Eds. Sandra Bermann and Catherine Porter. New Jersey: John Wiley \& Sons Ltd, 2014, pp. 15-27. https://www.academia.edu/6311299/The_Changing_Landscape of Translation and_Interpreting_Studies. Web. 29 Nov. 2017.

Bassett, Susan and Harish Trivedi, eds. Postcolonial Translation: Theory and Practice. London: Routledge, 1998. Print.

Dunne, Keiran. “A Copernican Revolution”. Perspectives on Localizationi. Ed. Keiran Dunne.Amsterdam: John Benjamins, 2016, p. 119-152. http://logisticsapi.brain.com.ua/perspectives-on-localization-dunne-keiran-j.pdf. $\quad$ Web. 06 May. 2017.

Geert Hofstede, Gert Jan Hofstede, Michael Minkov, eds. Cultures and Organizations: Software of the Mind. 3rd Edition, New York: McGraw-Hill, 2010. Print.

Gentzler, Edwin. Contemporary Translation Theories. London: Routledge, 1993. Print

Lefevere, André, ed. Translation/History/Culture: A Sourcebook. London: Routledge, 1992. Print.

House, Juliane. Translation Quality Assessment. Tübingen: Naar, 1977. Print

Nord, Christiane. "Defining translation functions. The translation brief as a guideline for the trainee translation" ILHA DO DESTERRO - A Journal of English Language, Literature in English and Cultural Studies. No. 33 ,1997,pp.41-55. https://periodicos.ufsc.br/index.php/desterro/article/view/9208/9484. Web. 14 Nov. 2017.

Pym, Anthony. "Localization from the Perspective of Translation Studies: Overlaps in the Digital Divide?”. Intercultural Studies Group. Tarragona, Spain: Universitat Rovirai Virgili, 2004, pp. 2-8. http://www.fut.es/ apym/. Web. 07 May. 2017.

Susan, Sarcevic, Insights Into Specialized Translation. Volume 46 of Linguistic Insights: Studies in Language and Communication. Eds. Maurizio Gotti and Susan Sarcevic. Berlin: Peter Lang. Print.

Snell-Hornby, Mary. Translation Studies: An Integrated Approach. Amsterdam: Benjamins, 1988. Print.

Trompenaars, Fons and Charles Hampden-Turner. Riding the Waves of Culture. $2^{\text {nd }}$ edition. London: Nicholas Brealey Publishing Ltd, 2012. Print

Tulloch, Sara, ed. Oxford Dictionary of New Worlds. Oxford: Oxford University Press, 1991. Print. 
LISA. "Report of the Education Initiative Taskforce of the Localization Industries Standards Association.” 1998. leit.lisa.org/pubs/public.pdf. https://books.google.ro/books?id=dN_s-

Ox6EU4C\&pg=PA112\&lpg=PA112\&dq=\%E2\%80\%9Cinvolves+taking $+\mathrm{a}+\mathrm{pr}$ oduct+and+making+it+linguistically+and+culturally+appropriate+to+the+targe $\underline{\mathrm{t}+\text { locale }+(\text { country/region+and+language })+\text { where }+\mathrm{it}+\text { will+be+used }+ \text { and }+ \text { sold } \%}$ 22\&source=bl\&ots=dWNqsBM1EK\&sig=ACfU3U2PIO1DDyWFpcqglZb9bx 8-OFp1bQ\&hl=en\&sa $=$ X\&ved=2ahUKEwiB uj0PnfAhUGmrQKHReYCj4Q6AEwB3oECAMQAQ\#v=onepage\&q=LISA\&f= false. Web. 12 Dec. 2017.

YouTube Official Channels: Coca Cola, MacDonald's, Heineken, Mercedes-Benz, Pantene, Nestlé, Dr Oetker, Dacia Romania. Web. 12 Dec. 2017. 